\title{
Study of Umbelliferone Hydroxylation to Esculetin Catalyzed by Polyphenol Oxidase
}

\author{
Mary of the Sea Garcia-Molina, Joseph Louis Munoz-Munoz, Francis Garcia-Molina, \\ Joseph Neptune Rodriguez-Lopez, and Francis Garcia-Canovas* \\ Investigation Group of Enzimology (GENZ), Department of Biochemistry and Molecular Biology A, University of \\ Murcia, Campus of International Excellence "Campus Mare Nostrum”; E-30100, Espinardo, Murcia, Spain. \\ Received February 6, 2013; accepted April 26, 2013
}

\begin{abstract}
We characterize umbelliferone, a derivative of 2,4-dihydroxycoumaric acid, as a substrate of polyphenol oxidase. This enzyme hydroxylates umbelliferone to esculetin, its $o$-diphenol, and then oxidizes it to $o$-quinone. The findings show that umbelliferone, an intermediate in one of the coumarin biosynthesis pathways, may be transformed into its $o$-diphenol, esculetin, which is also an intermediate in the same pathway. The activity of the enzyme on umbelliferone was followed by measuring the consumption of oxygen, spectrophotometrically and by HPLC. Kinetic constants characterizing the hydroxylation process were: $k_{\text {cat }}=0.09 \pm 0.02 \mathrm{~s}^{-1}$ and $K_{\mathrm{m}}=0.17 \pm 0.06 \mathrm{~mm}$. The $o$-diphenol, esculetin, was a better substrate and when its oxidation was followed spectrophotometrically, the kinetic constants were: $k_{\text {cat }}=1.31 \pm 0.25 \mathrm{~s}^{-1}$ and $K_{\mathrm{m}}=0.035 \pm 0.002 \mathrm{~mm}$. Both compounds therefore can be considered as alternative substrates to L-tyrosine and L-3,4-dihydroxyphenylalanine (L-DOPA), since both indirectly inhibit melanogenesis.
\end{abstract}

Key words tyrosinase; esculetin; umbelliferone; polyphenol oxidase

Tyrosinase or polyphenol oxidase (EC 1.14.18.1; PPO) is a binuclear copper cluster ubiquitously present in biological systems. It catalyzes two types of reactions in which molecular oxygen participates: (a) The orthohydroxylation of monophenols to $o$-diphenols (monophenolase activity) and (b) the oxidation of $o$-diphenols to their corresponding $o$-quinones (diphenolase activity). ${ }^{1)}$

Three enzymatic species participate in the catalytic cycle of PPO, Chart 1: met-PPO $\left(E_{\mathrm{m}}\right)$, deoxy-PPO $\left(E_{\mathrm{d}}\right)$ and oxy-PPO $\left(E_{\text {ox }}\right)$. Note that when the $E_{\text {ox }}$ form of the enzyme acts on a monophenol (M), the $o$-diphenol formed may be oxidized to $o$-quinone or be released, giving $E_{\mathrm{d}}$ or $E_{\mathrm{m}}$, respectively. ${ }^{2)}$ To return to the hydroxylase catalytic cycle, the enzyme that has passed from $E_{\mathrm{ox}}$ to $E_{\mathrm{m}}$ must react with the $o$-diphenol (D). When $o$-quinones (e.g., $o$-dopaquinone), which are unstable, evolve to give $o$-diphenol in the medium, the enzyme shows a lag period until the steady state is reached, ${ }^{2)}$ but when the $o$-quinone in its evolution does not accumulate $o$-diphenol the system shows hardly any activity. This last situation is evident when PPO acts on 4-tert-butylphenol. ${ }^{3)}$

In the hydroxycoumarin biosynthesis pathway starting from cinnamic acid, 7-hydroxycoumarin (umbelliferone), the common name of umbelliferone, is formed after a series of reactions, and from this compound, 6,7-dihydroxycoumarin (esculetin), 7-hydroxy-6-methoxycoumarin (scopoletin) and esculin are formed ${ }^{4,5}$ (Chart 2). The coumarins are especially abundant in the Umbelliferae and Rutaceae families. ${ }^{6,7)}$ Some coumarins from natural sources have also been used as therapeutic agents for humans, ${ }^{8)}$ and their antibacterial, antifungal and anticancer activities make these compounds attractive for further derivatization and screening for use as therapeutic agents. $^{9)}$

Esculetin (6) has been described as an inhibitor of lipoxygenase (LOX) ${ }^{10)}$ and it has been demonstrated that the products resulting from the oxidation of $\mathbf{6}$ by peroxidase (POD) and PPO contribute to the defence against pathogens, increas-

The authors declare no conflict of interest.

*To whom correspondence should be addressed. e-mail: canovasf@um.es ing their fungitoxicity 20 -fold. ${ }^{11}$

According to Chart 2, umbelliferone (5) would seem to be the precursor of $\mathbf{6}$, although previous studies have suggested that umbelliferone is hydroxylated by a P450 monooxygenase. ${ }^{12)}$ In Arabidopsis thaliana it has been demonstrated that the genetic mutation of the gene encoding CYP98A3, reduces the biosynthesis of scopoletin (8) and scopolin (9), and it has been proposed that this enzyme may bring about the 3 '-hydroxylation of $p$-coumaric acid. Furthermore, the same authors observed an increase in a derivative of $\mathbf{5}$ (umbelliferone glucoside). ${ }^{13)}$ A detailed study of the biosynthetic pathways to hydroxycoumarins during post-harvest physiological deterioration in Cassava roots using stable isotope labelling pointed to

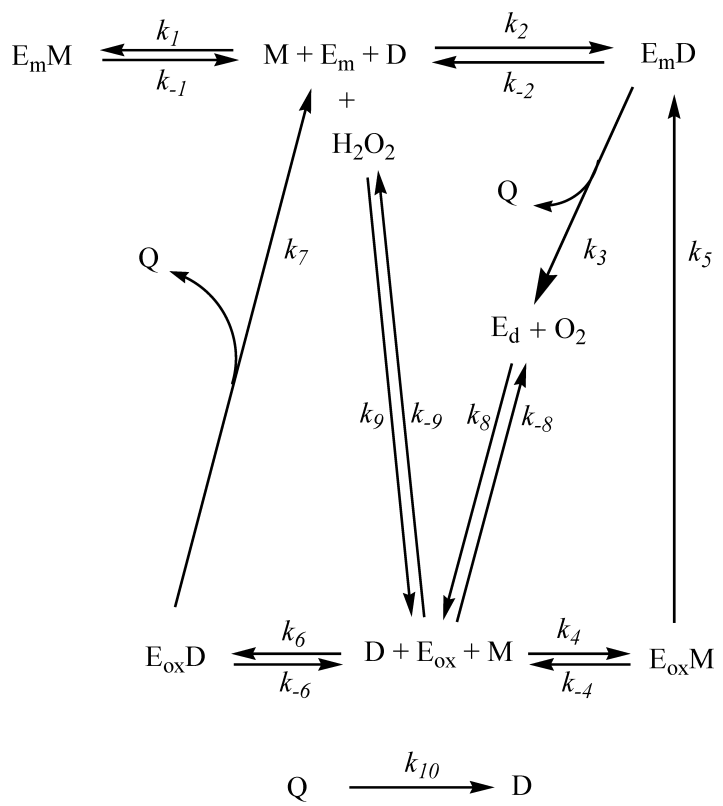

Chart 1. Kinetic Mechanism Proposed to Explain the Action of Polyphenol Oxidase on Monophenols

$E_{\mathrm{m}}=m e t-\mathrm{PPO}, E_{\mathrm{d}}=$ deox $y-\mathrm{PPO}, E_{\mathrm{ox}}=o x y-\mathrm{PPO}, \mathrm{D}=o$-diphenol, $\mathrm{M}=$ monophenol, $\mathrm{Q}=o$-quinone. 


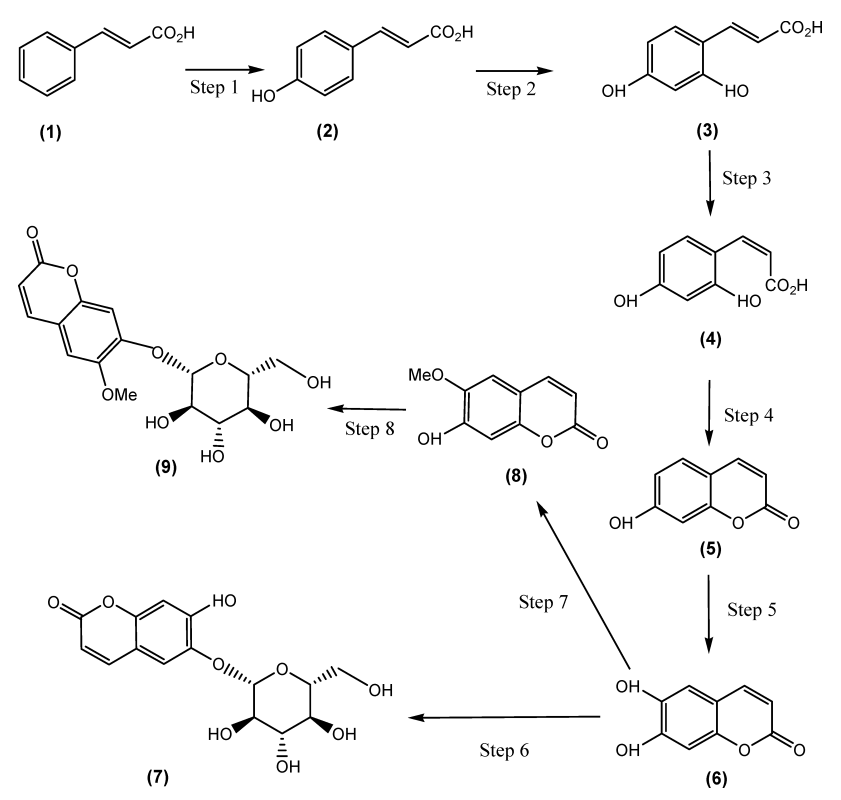

Chart 2. Biosynthesis of Hydroxycoumarins

Chemical structures of cinnamic acid (1), 4-coumaric acid (2), 2,4 dihydroxycoumaric acid (3), 2,4-dihydroxy-cis-cinnamic acid (4), umbelliferone (5), esculetin (6), esculin (7), scopoletin (8) and scopolin (9).

two pathways emerging from $p$-coumaric acid: the main one through caffeic and ferulic acids, giving rise to $\mathbf{8}$ and $\mathbf{9}$, and the other through 5 giving rise to 6 and esculin (7) (Chart 2 ). In the above pathways different hydroxylation steps were proposed, but involving cytochrome P450 enzymes. ${ }^{5)}$ Despite the use of several experimental approaches, the possibility that $\mathbf{5}$ is hydroxylated to $\mathbf{6}$ by PPO was recently discarded when it was seen that $\mathbf{5}$ behaves as a true competitive inhibitor of PPO, with a $K_{\mathrm{i}}$ of $14 \mu \mathrm{M}$, when it is studied by measuring the monophenolase activity with L-tyrosine as substrate. ${ }^{4)}$

Recently, coumarin-resveratrol hybrids have been synthesized as potential inhibitors of PPO. For example, the compound 3-(3',4',5'-trihydroxyphenyl)-6,8-dihydroxy-coumarin, when the tyrosinase activity was assayed with L-3,4-dihydroxyphenylalanine (L-DOPA) as substrate, was seen to be more potent than 5 with $\mathrm{IC}_{50}(\mathrm{~mm})$ values of 0.27 and 0.42 , respectively. ${ }^{14)}$ Based on the structure of coumarins new compounds have been synthesized: for example, halogenated derivates of phenylcoumarins to increase the inhibitory power towards PPO, more specifically the 3-phenylcoumarins with one atom of bromide. $\left.{ }^{15}\right)$ Coumarin derivatives with thiosemicarbazide moieties have also been described, the compound 2-(1-(coumarin-3-yl)ethylidene) hydrazinecarbothioamide showing an $\mathrm{IC}_{50}$ value of $3.44 \mu \mathrm{M}^{16)}$ A revision of the antioxidant effects of these compounds (umbelliferone and esculetin) has recently been published ${ }^{17)}$ and neuroprotective effects have been described in a mouse model of Parkinson's disease. ${ }^{18)}$

The aim of this work was to study the reaction of PPO with 5 and $\mathbf{6}$, further clarifying the coumarin biosynthesis pathway. We focus on the enzymatic mechanism depicted in Chart 1, which underlines the need for $o$-diphenol to be present in the reaction medium for the enzyme to make catalytic cycles with the monophenols (to generate the oxy form from the met form). In our case, the $o$-diphenol is $\mathbf{6}$ and the monophenol is 5. It is shown how the presence of a reductant (e.g., ascorbic acid) or $\mathrm{H}_{2} \mathrm{O}_{2}$ has the same effect, that is, they encourage the enzyme to act on the monophenols.

\section{MATERIALS AND METHODS}

Enzyme Source Mushroom polyphenol oxidase (4276U/ $\mathrm{mg}$ ) was purchased from Sigma (Madrid, Spain) and was purified as described in ref. 19, laccase from Agaricus bisporus (5.1 U/mg) was purchased from Fluka, Madrid (Spain). The protein concentration was determined by Bradford's method ${ }^{20)}$ using bovine serum albumin as the standard.

Reagents L-Tyrosine, L-DOPA, umbelliferone (5), esculetin (6) 4-tert-butylcatechol (TBC) and ABTS (2,2'-azinobis(3-ethylbenzothiazoline-6-sulfonic acid) diammonium salt) were purchased from Sigma (Madrid, Spain). Stock solutions of the reducing substrates were prepared in $0.15 \mathrm{~mm}$ phosphoric acid to prevent autooxidation, except 5, which was prepared in $2 \mathrm{~mm}$ phosphate buffer $\mathrm{pH}=7.0$.

Spectrophotometric Assays When the substrate was $\mathrm{TBC}$, the enzymatic reaction was followed by monitoring the formation of o-tert-butylquinone at $410 \mathrm{~nm}(\varepsilon=$ $\left.1200 \mathrm{M}^{-1} \mathrm{~cm}^{-1}\right){ }^{21)}$ When the substrate was L-tyrosine or LDOPA the increase in absorbance at $475 \mathrm{~nm}\left(\varepsilon=3500 \mathrm{M}^{-1} \mathrm{~cm}^{-1}\right)$ was monitored. $^{21)}$ The oxidation of 6 was monitored at $295 \mathrm{~nm}$ by measuring the consumption of the ascorbic acid during the oxidation of this acid by the $o$-quinone generated by the enzyme.

The reaction of PPO with $\mathbf{5}$ was followed by measuring spectrophotometrically, the $o$-quinone formed as a result of $\mathbf{6}$ oxidation by periodate in excess.

Oxymetric Assays Measurements of dissolved oxygen concentration were made with a Hansatech (Kings Lynn, Cambs, U.K.) oxygraph unit controlled by a PC. The oxygraph used a Clark-type silver/platinum electrode with a $12.5 \mu \mathrm{m}$ Teflon membrane. The sample was continuously stirred during the experiments and its temperature was maintained at $25^{\circ} \mathrm{C}$. The zero oxygen level for calibration and experiments was obtained by bubbling oxygen-free nitrogen through the sample for at least $10 \mathrm{~min}$. The oxygraph was calibrated as described in ref. 22. The reaction of PPO with $\mathbf{5}$ was followed by measuring, the consumption of oxygen oxymetrically.

Chromatography The reaction of PPO with $\mathbf{5}$ was followed also measuring the formation of $\mathbf{6}$ in the presence of ascorbic acid by HPLC. The enzyme was separated from the reaction intermediates by centrifugation using 10000 MWCO filters. The reaction products were analyzed in a high resolution liquid chromatograph (VWR-Hitachi, model Elite LaChrom). Samples were introduced via a fixed volume $(20 \mu \mathrm{L})$. The compounds were separated in a Teknokroma C-18 column $(25 \mathrm{~cm} \times 0.4$, i.d. $5 \mu \mathrm{m})$ and eluted at a flow rate of $1 \mathrm{~mL} / \mathrm{min}$ with the mobile phase formed by the dissolutions (A) Agua milli Q with 3\% acetic acid and (B) HPLC grade acetonitrile with $3 \%$ acetic acid. The following gradient programme was used: $0 \mathrm{~min}, 94 \% \mathrm{~A} ; 15 \mathrm{~min}, 82 \% \mathrm{~A} ; 25 \mathrm{~min}$, $67 \% \mathrm{~A} ; 30 \mathrm{~min}, 94 \% \mathrm{~A}$. Measurements were made at $259 \mathrm{~nm}$, $324 \mathrm{~nm}$ and $359 \mathrm{~nm}^{23)}$

Kinetic Data Analysis of Monophenolase and Diphenolase Activities Initial rate values $V_{0}$ were calculated from triplicate measurements at each reducing substrate concentration. The data were fitted by nonlinear regression to the Michaelis-Menten equation, using the Sigma Plot 9.0 program for Windows ${ }^{\circledR}{ }^{24)}$ 


\section{RESULTS AND DISCUSSION}

When attempts are made to characterize a monophenol as possible substrate for PPO, problems may arise-for example, no enzymatic activity is detected or, if the monophenol is assayed by measuring the enzyme activity on L-tyrosine or L-DOPA and following the increase in absorbance caused by the formation of dopachrome at a wavelength of $475 \mathrm{~nm}$, the dopachrome formation rate usually diminishes since most monophenols, including $\mathbf{5}$, give rise to $o$-quinones with low molar absorptivity coefficients and so, in its presence, the formation of dopachrome is slowed, and, consequently, such monophenols are usually classified as inhibitors.

When studying the action of $\mathbf{5}$ and $\mathbf{6}$ on PPO activity by measuring the monophenolase and diphenolase activities on Ltyrosine or L-DOPA, the effects described above normally lead to them being described as powerful inhibitors of PPO: 6 with an $\mathrm{IC}_{50}=0.043 \mathrm{~mm}$ when assayed with L-DOPA as substrate, ${ }^{6}$ and $\mathbf{5}$ with a $K_{\mathrm{I}}=0.014 \mathrm{mM}$ when assayed with L-tyrosine as substrate. ${ }^{4)}$ Moreover, the characterization of possible tyrosinase substrates is complicated by the fact that the reaction product (an $o$-quinone) is usually unstable.

In a previous work using a chronometric method, ${ }^{21,25,26)}$ we characterized 6 not as a PPO inhibitor but as a true substrate of the same, a conclusion also reached by other authors. ${ }^{4)}$ However, $\mathbf{5}$ has been classified as an inhibitor, ${ }^{4)}$ a fact that can be explained if we take into consideration the enzyme's action mechanism depicted in Chart 1 (see below).

Behaviour of 5 and 6 as Apparent Inhibitors of the Activity of PPO on L-Tyrosine and L-DOPA Table 1 shows the apparent \% inhibition of PPO activity exercised by $\mathbf{5}$ and 6 on the monophenolase and diphenolase of PPO when measured with L-tyrosine or L-DOPA, respectively. When the inhibition of PPO by 6 is studied, this substrate apparently inhibits both the activity on L-tyrosine and L-DOPA more strongly, because it is a better substrate for the enzyme than 5. However, the inhibition of PPO by a monophenol, like $\mathbf{5}$, or by an $o$-diphenol, like 6, is greater in the case of the monophenolase activity of PPO on L-tyrosine, since in this case the enzyme is partly inhibited by the L-tyrosine itself (see Chart 1). Moreover, the binding of the monophenols to the met form is strong since it is facilitated by a base probably a histidine. ${ }^{27)}$

Physico-Chemical Characteristics of 5 and 6 The monophenol 5 has a $\mathrm{p} K_{\mathrm{a}}$ value of 6.89, which is low compared with other monophenols, and this is similarly the case with $\mathbf{6}$ ( $\left.\mathrm{p} K_{\mathrm{a}}=7.64\right)$. The existence of this $\mathrm{p} K_{\mathrm{a}}$ is confirmed in Fig. 1 and Fig. 1 inset, by the appearance of the isosbestic points. Furthermore, the high chemical shift values $(\delta)$ for the carbon atoms supporting the hydroxyl group $\left(\delta_{1}=158.1 \mathrm{ppm}\right.$ for $\mathbf{5}$ and $\delta_{1}=146.9 \mathrm{ppm}$ and $\delta_{2}=144 \mathrm{ppm}$ for 6) suggests that both are very bad substrates for PPO, as will be confirmed below.

Considerations on the PPO Action Mechanism The kinetic mechanism of PPO in its activity on monophenols and $o$-diphenols is described in Chart 1 , where it can be seen that for PPO to act on a monophenol the presence of an $o$-diphenol is necessary. In the case of monophenols that give rise to unstable $o$-quinones (for example $o$-dopaquinone) that can accumulate $o$-diphenol in the medium as they evolve, the enzyme reaches the steady state after a lag period, which is the time the system needs to accumulate the $o$-diphenol concentration to reach the steady state. ${ }^{28)}$ In the case of $\mathbf{5}$, the $o$-quinone
Table 1. Percentage Inhibition of Monophenolase and Diphenolase Activities of Polyphenol Oxidase in the Presence of 5 or $\mathbf{6}$

\begin{tabular}{cccc}
\hline Substrates & $\begin{array}{c}\text { Concentration } \\
(\mathrm{mm})\end{array}$ & $\begin{array}{c}\text { Monophenolase }^{a)} \\
\text { activity (\%) }\end{array}$ & $\begin{array}{c}\text { Diphenolase }^{b)} \\
\text { activity (\%) }^{(\%)}\end{array}$ \\
\hline $\mathbf{5}$ & 0.1 & 52.9 & 10.8 \\
& 0.3 & 74.3 & 35.6 \\
\multirow{6}{6}{6} & 0.5 & 82.9 & 49.5 \\
& 0.1 & 81.2 & 63.4 \\
& 0.3 & 84.6 & 79.3 \\
& 0.5 & 86.3 & 86.8 \\
\hline
\end{tabular}

a) Monophenolase activity, the experimental conditions were: phosphate buffer $30 \mathrm{~mm}, \mathrm{pH}=6.0$ at $25^{\circ} \mathrm{C},[\mathrm{E}]_{0}=50 \mathrm{~nm},[\mathrm{~L}-\text { tyrosine }]_{0}=0.26 \mathrm{~mm}, \quad[\mathrm{~L}-\mathrm{DOPA}]_{0} /[\mathrm{L}-$ tyrosine $]_{0}=0.046$. Umbelliferone, (5) $(\mathrm{mm}): 0.1,0.3$ and 0.5 . Esculetin, (6) (mM): $0.1,0.2$ and $0.5 . b$ ) Diphenolase activity, the experimental conditions were: phosphate buffer $30 \mathrm{~mm}, \mathrm{pH}=6.0$ at $25^{\circ} \mathrm{C},[\mathrm{E}]_{0}=15 \mathrm{~nm},[\mathrm{~L}-\mathrm{DOPA}]_{0}=0.5 \mathrm{~mm}$. Umbelliferone (5) and esculetin (6), the same concentrations as used for monophenolase activity.

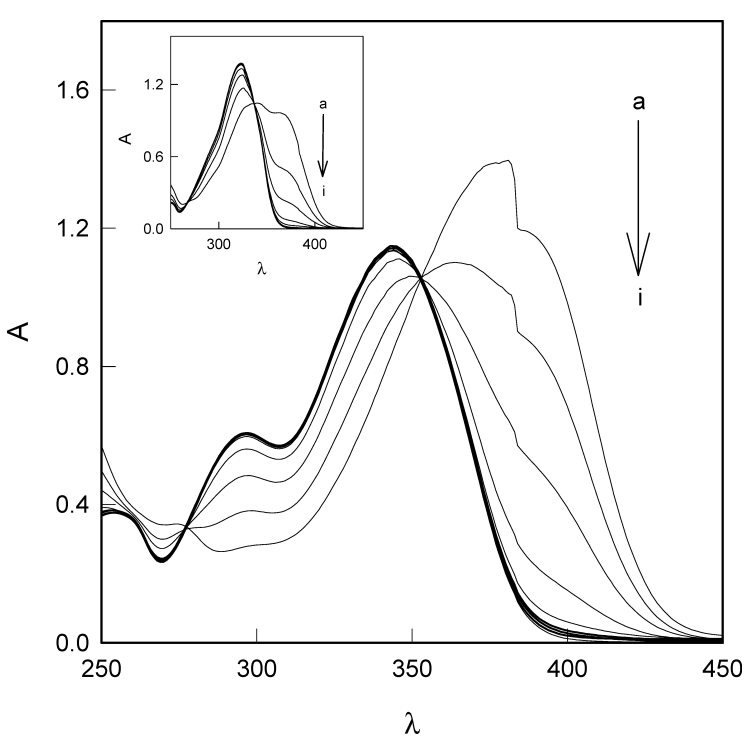

Fig. 1. Spectrophotometric Recordings of $\mathbf{6}$ and $\mathbf{5}$ at Different $\mathrm{pH}$ Values

The experimental conditions for 6 were: [esculetin $]_{0}=0.1 \mathrm{~mm}$, phosphate buffer $30 \mathrm{~mm}$, at $25^{\circ} \mathrm{C}$, at values pH: 8.3 (a), 7.9 (b), 7.3 (c), 7.1 (d), 6.6 (e), 6.0 (f) and 5.5 (g) and acetate buffer $30 \mathrm{~mm}$ at $\mathrm{pH}$ values of 5.3 (h) and 4.5 (i). Inset. The experimental conditions for 5 were [umbelliferone] $]_{0}=0.1 \mathrm{~mm}$ and the same $\mathrm{pH}$-values as in Fig. 2.

does no accumulate $o$-diphenol in the medium $\left(k_{10}=0\right.$, Chart 1 ), as occurs in the case of the $o$-dopaquinone, and it is necessary to add a small quantity of $o$-diphenol for the system to show activity. When the oxygen consumption rate is measured in the action of PPO on 5, by adding $\mathbf{6}$ at a constant ratio (R), $\mathrm{R}=[\text { esculetin }]_{0} /[\text { umbelliferone }]_{0}=0.02,{ }^{28)}$ a rate in oxygen consumption was observed (results not shown). The dependence of the oxygen consumption rate on the concentration of umbelliferone was hyperbolic. Nonlinear analysis of these data according the Michaelis equation gives the values of $k_{\text {cat }}$ and $K_{\mathrm{m}}$ as $0.09 \pm 0.02 \mathrm{~s}^{-1}$ and $0.17 \pm 0.06 \mathrm{~mm}$, respectively.

To confirm that the product of PPO acting on $\mathbf{5}$ is $\mathbf{6}$ (Fig. 2), PPO was made to react with $\mathbf{5}$ in the presence of ascorbic acid in different conditions: Fig. $2 \mathrm{a}(\diamond)$ with catalytic quantities of 6, Fig. 2b ( $\mathbf{\Delta})$ with catalytic quantities of TBC, and Fig. 2c (O) in the absence of $o$-diphenol. At given times, an aliquot was oxidized by periodate in excess and the absorbance corresponding to the $o$-quinone of $\mathbf{6}$ was monitored (see Fig. 2). As can be seen, the absorbance increased with the incubation 


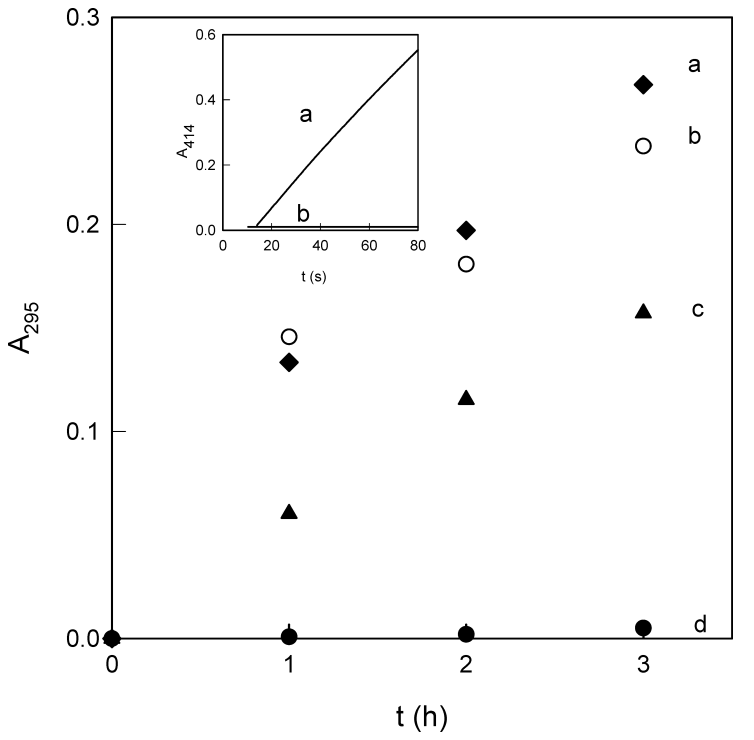

Fig. 2. Reaction of Polyphenol Oxidase with $\mathbf{5}$ in the Presence of Ascorbic Acid, in Different Experimental Conditions

At the times indicated in the figure, an aliquot was oxidized with excess sodium periodate, and the absorbance at $460 \mathrm{~nm}$ was measured. The experimental conditions were: phosphate buffer $30 \mathrm{~mm}, \mathrm{pH}=6.0$ at $25^{\circ} \mathrm{C}$, [ascorbic acid] $]_{0}=3 \mathrm{~mm}$, [umbelliferone $]_{0}=0.5 \mathrm{~mm},[\mathrm{E}]_{0}=0.46 \mu \mathrm{M}$. (a) ( $\left.\diamond\right)$ At time $t=0$, [esculetin $]_{0}=0.01 \mathrm{~mm}$ was added. (b) (A) At time $t=0,[\mathrm{TBC}]_{0}=0.01 \mathrm{~mm}$ was added. (c) $(\bigcirc)$ No $o$-diphenol was added at $t=0$. (d) ( ) Mushroom laccase $(0.15 \mathrm{mg} / \mathrm{mL})$ was added instead of polyphenol oxidase. Inset. Spectrophotometric recording of the increase in absorbance at $414 \mathrm{~nm}$, in phosphate buffer $30 \mathrm{~mm}, \mathrm{pH} 6.0$ at $25^{\circ} \mathrm{C}$ in the action of laccase on $[\mathrm{ABTS}]_{0}=2.4 \mathrm{~mm}$. (b) Spectrophotometric recording of the increase in absorbance in the same experimental conditions as (a) but in the absence of laccase and a PPO concentration of $0.46 \mu \mathrm{M}$.

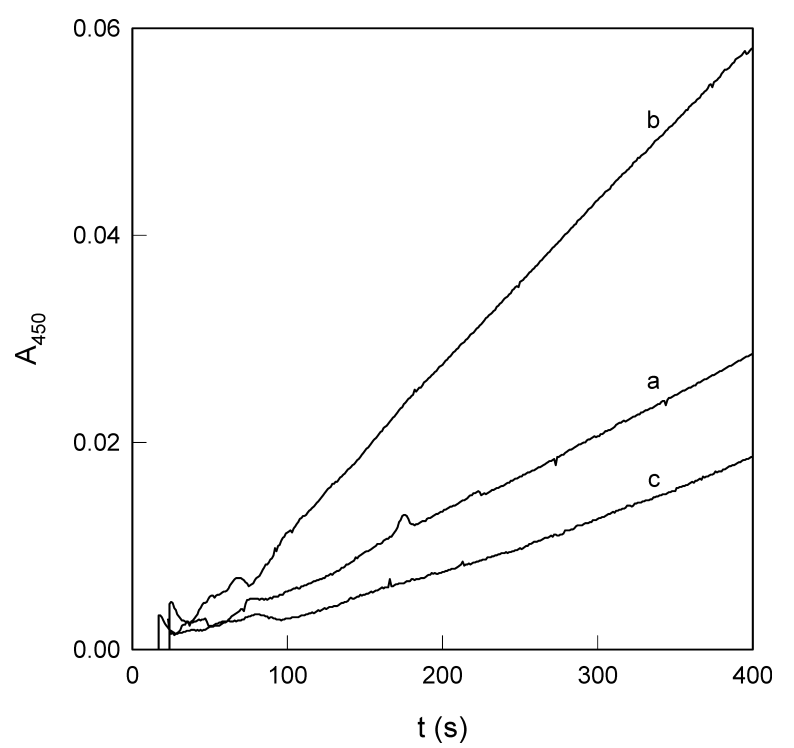

Fig. 3. Peroxygenase Activity of Polyphenol Oxidase on $\mathbf{5}$

Spectrophotometric recordings of the increase in absorbance at $450 \mathrm{~nm}$ in the action of polyphenol oxidase on $\mathbf{5}$ in the presence of $\mathrm{H}_{2} \mathrm{O}_{2}$ in $30 \mathrm{~mm}$ phosphate buffer, $\mathrm{pH}=6.0$. Curve (a), The experimental conditions were: [umbelliferone $]_{0}=0.5 \mathrm{~mm}, \quad\left[\mathrm{H}_{2} \mathrm{O}_{2}\right]_{0}=10 \mathrm{~mm}$ and $[\mathrm{E}]_{0}=0.1 \mu \mathrm{M}$. Curve (b), [umbelliferone $]_{0}=0.5 \mathrm{~mm}, \quad\left[\mathrm{H}_{2} \mathrm{O}_{2}\right]_{0}=10 \mathrm{~mm}$ and $[\mathrm{E}]_{0}=0.2 \mu \mathrm{m}$. Curve (c), [umbelliferone $]_{0}=0.1 \mathrm{~mm},\left[\mathrm{H}_{2} \mathrm{O}_{2}\right]_{0}=10 \mathrm{~mm}$ and $[\mathrm{E}]_{0}=0.1 \mu \mathrm{M}$.

time. Note that the enzyme laccase cannot form 6, Fig. $2 d(\mathbf{O})$.

It is known that mushroom PPO may be contaminated by laccase. However, Fig. 2 Inset curve (a) shows the activity of mushroom laccase on ABTS and Fig. 2 Inset curve (b) the absence of activity when the experiment is carried out at

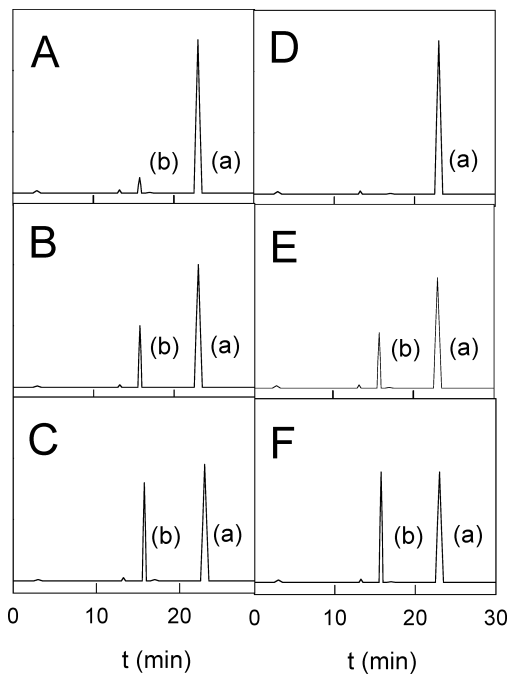

Fig. 4. HPLC Analysis of the Reaction of Polyphenol Oxidase with $\mathbf{5}$ in Different Experimental Conditions

5 (a) $(0.5 \mathrm{~mm})$ was reacted with polyphenol oxidase $(0.59 \mu \mathrm{M})$ in $30 \mathrm{~mm}$ phosphate buffer, $\mathrm{pH}=6.0$ in the presence of $3 \mathrm{~mm}$ ascorbic acid, adding to the reaction medium $10 \mu \mathrm{M} 6$ (b) (A-C) or $10 \mu \mathrm{M} \mathrm{TBC}(\mathrm{D}-\mathrm{F})$. At times $t=0, t=2 \mathrm{~h}$ and $t=3 \mathrm{~h}$, an aliquot was taken, filtered to separate the enzyme and $20 \mu \mathrm{L}$ were injected into the HPLC apparatus. The rest of the conditions are described in Materials and Methods.

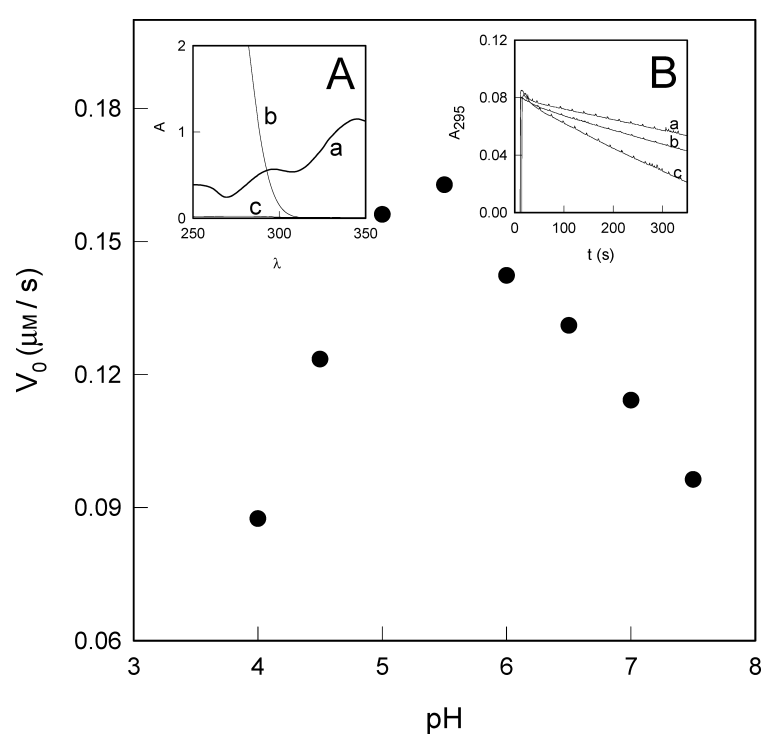

Fig. 5. Variation in the Initial Rate of Polyphenol Oxidase on 6 vs. pH

Experimental conditions: [esculetin $]_{0}=0.1 \mathrm{~mm}, \quad[\text { ascorbic acid }]_{0}=300 \mu \mathrm{M}$ and $[\mathrm{E}]_{0}=62 \mathrm{~nm}$, phosphate buffer $30 \mathrm{~mm} \mathrm{pH}: 7.3 ; 7.1 ; 6.6 ; 6.0 ; 5.5$ and $30 \mathrm{~mm}$ acetate buffer at $\mathrm{pH} 5.3 ; 4.5$ and 4.0. Inset A. Overlapping of 6, ascorbic acid and PPO spectra. Spectrophotometric recordings: (a) [esculetin $]_{0}=0.1 \mathrm{~mm}$, (b) [ascorbic acid $]_{0}=300 \mu \mathrm{M}$ and (c) $[\mathrm{E}]_{0}=62 \mathrm{~nm}$. Inset B. Oxidation of 6 . Spectrophotometric recordings of disappearance of ascorbic acid resulting from the reduction of the $o$-quinone of $\mathbf{6}$, monitored at $295 \mathrm{~nm}$. The experimental recordings were those described in Fig. 4 at the following pH-values: (a) 4.0, (b) 7.3 and (c) 6.0.

the concentration indicated in Fig. 2. The same experiments as in Fig. 2d (O), carried out with laccase, show no increase in absorbance so that laccase is incapable of attacking $\mathbf{5}$ and originating 6.

Another way to reveal the action of PPO on $\mathbf{5}$ consists in that this enzyme can act in its peroxygenase activity. ${ }^{29-31)}$ In the presence of $\mathrm{H}_{2} \mathrm{O}_{2}$, the formation of the oxy form of PPO (Chart 1) from $E_{\mathrm{m}}$ was followed, since it is capable of attack- 
ing the 5, hydroxylating and oxidizing it (Fig. 3). These experiments demonstrated the typical characteristics of this activity on monophenols, curve (a) representing a control experiment. It can be seen that as the concentration of enzyme increases, Fig. 3 curve (b), the rate increases and the lag period diminishes. When the substrate concentration decreases, so do the rate and lag period, Fig. 3, curve (c).

The clearest evidence of $\mathbf{5}$ being hydroxylated to $\mathbf{6}$ is obtained by using HPLC (Fig. 4). In this case, 5, ascorbic acid and PPO were reacted in the presence of catalytic quantities $(10 \mu \mathrm{M})$ of 6 or $o$-diphenol TBC. At the times indicated in Fig. 4, aliquots were taken and injected into the HPLC apparatus, giving the following results: Fig. 4A, at $t=0$; Fig. 4B, at $t=2 \mathrm{~h}$ and Fig. $4 \mathrm{C}$ at $t=3 \mathrm{~h}$, when 6 was added and Fig. 4D, at $t=0$; Fig. 4E, at $t=2 \mathrm{~h}$ and Fig. $4 \mathrm{~F}$ at $t=3 \mathrm{~h}$, when TBC was added. Note the accumulation of $\mathbf{6}$ with time. Therefore, the enzyme hydroxylates 5 to $\mathbf{6}$ and then oxidizes this to $o$-quinone, which is reduced by ascorbic acid to form $\mathbf{6}$ again.

The present work takes another look at the oxidation of 6 by PPO (Fig. 5). Taking into account the spectra of ascorbic acid and 6, Fig. 5 inset A, $295 \mathrm{~nm}$ was chosen to follow the rate of disappearance of the ascorbic acid used in the reduction of the $o$-quinone of 6 (Fig. 5 inset B). The dependence of this rate on the $\mathrm{pH}$ can be seen in Fig. $5 .^{32,33)}$ Note the bell shaped curve $\mathrm{e}^{34)}$ indicating the existence of two $\mathrm{p} K_{\mathrm{a}} \mathrm{s}$ in the free enzyme. Analysis of the initial rate versus $\mathbf{6}$ concentration by nonlineal regression provides the values $k_{\text {cat }}$ and $K_{\mathrm{m}}$ (not shown). It is interesting that the $k_{\text {cat }}$ for diphenol $\mathbf{6}$ is greater than that for $\mathbf{5}$ : $k_{\text {cat }}=1.31 \pm 0.25 \mathrm{~s}^{-1}$ and $0.09 \pm 0.02 \mathrm{~s}^{-1}$, respectively.

\section{CONCLUSION}

In conclusion, we have characterized $\mathbf{5}$ as a substrate of PPO. 5 is seen to be a very bad substrate for polyphenol oxidase, which agrees with the high $\delta$ value of the carbon bearing the hydroxyl group. Furthermore, at physiological $\mathrm{pH}$, its hydroxyl group is highly deprotonated as a consequence of the low value of $\mathrm{p} K_{\mathrm{a}}$. These results throw light on part of the coumarin biosynthesis pathway and help explain the participation of PPO in the pathway.

Acknowledgments This paper was partially supported by Grants from the Ministerio de Educación y Ciencia (Madrid, Spain), project BIO2009-12956; Fundación Séneca (CARM, Murcia, Spain), projects 08856/PI/08 and 08595/PI/08, and the Consejería de Educación (CARM, Murcia, Spain), BIO-BMC 06/01-0004. JLMM holds a fellowship from the Fundación Caja Murcia (Murcia, Spain).

\section{REFERENCES}

1) Sánchez-Ferrer A, Rodríguez-López JN, García-Cánovas F, GarcíaCarmona F. Tyrosinase: a comprehensive review of its mechanism. Biochim. Biophys. Acta, 1247, 1-11 (1995).

2) Rodríguez-López JN, Fenoll LG, Peñalver MJ, García-Ruiz PA, Varón R, Martínez-Ortíz F, García-Cánovas F, Tudela J. Tyrosinase action on monophenols: evidence for direct enzymatic release of $O$ diphenol. Biochim. Biophys. Acta, 1548, 238-256 (2001).

3) Ros JR, Rodríguez-López JN, Varón R, García-Cánovas F. Kinetics study of the oxidation of 4-tert-butylphenol by tyrosinase. Eur. J. Biochem., 222, 449-452 (1994).

4) Sollai F, Zucca P, Sanjust E, Steri D, Rescigno A. Umbelliferone and esculetin: inhibitors or substrates for polyphenol oxidases? Biol. Pharm. Bull., 31, 2187-2193 (2008).

5) Bayoumi SA, Rowan MG, Beeching JR, Blagbrough IS. Investigation of biosynthetic pathways to hydroxycoumarins during postharvest physiological deterioration in Cassava roots by using stable isotope labelling. ChemBioChem, 9, 3013-3022 (2008).

6) Masamoto Y, Murata Y, Baba K, Shimoishi Y, Tada M, Takahata K. Inhibitory effects of esculetin on melanin biosynthesis. Biol. Pharm. Bull., 27, 422-425 (2004).

7) Bourgaud F, Hehn A, Larbat R, Doerper S, Gontier E, Kellner S, Matern U. Biosynthesis of coumarins in plants a major pathway still to be unravelled for cytochrome P450 enzymes. Phytochem. Rev., 5, 293-308 (2006).

8) Mueller RL. First-generation agents: aspirin, heparin and coumarins. Best Pract. Res. Clin. Haematol., 17, 23-53 (2004).

9) Khode S, Maddi V, Aragade P, Palkar M, Ronad PK, Mamledesai S, Thippeswamy AH, Satyanarayana D. Synthesis and pharmacological evaluation of a novel series of 5-(substituted)aryl-3-(3coumarinyl)-1-phenyl-2-pyrazolines as novel anti-inflammatory and analgesic agents. Eur. J. Med. Chem., 44, 1682-1688 (2009).

10) Lord JC, Anderson S, Stanley DW. Eicosanoids mediate Manduca sexta cellular response to the fungal pathogen Beauveria bassiana: a role for the lipoxygenase pathway. Arch. Insect Biochem. Physiol., 51, 46-54 (2002).

11) Gómez-Vásquez R, Day R, Buschmann H, Randles S, Beeching JR, Cooper RM. Phenylpropanoids, phenylalanine ammonia lyase and peroxidases in elicitor-challenged cassava (Manihot esculenta) suspension cells and leaves. Ann. Bot. (Lond.), 94, 87-97 (2004).

12) Brown SA. Biosynthesis of 6,7-dihydroxycoumarin in Cichorium intybus. Can. J. Biochem. Cell Biol., 63, 292-295 (1985).

13) Kai K, Shimizu B, Mizutani M, Watanabe K, Sakata K. Accumulation of coumarins in Arabidopsis thaliana. Phytochemistry, 67, 379-386 (2006).

14) Fais A, Corda M, Era B, Fadda MB, Matos MJ, Quezada E, Santana L, Picciau C, Podda G, Delogu G. Tyrosinase inhibitor activity of coumarin-resveratrol hybrids. Molecules, 14, 2514-2520 (2009).

15) Matos MJ, Santana L, Uriarte E, Delogu G, Corda M, Fadda MB, Era B, Fais A. New halogenated phenylcoumarins as tyrosinase inhibitors. Bioorg. Med. Chem. Lett., 21, 3342-3345 (2011).

16) Liu J, Wu F, Chen L, Zhao L, Zhao Z, Wang M, Lei S. Biological evaluation of coumarin derivatives as mushroom tyrosinase inhibitors. Food Chem., 135, 2872-2878 (2012).

17) Kostova I, Bhatia S, Grigorov P, Balkansky S, Parmar VS, Prasad AK, Saso L. Coumarins as antioxidants. Curr. Med. Chem., 18, 3929-3951 (2011).

18) Subramaniam SR, Ellis EM. Neuroprotective effects of umbelliferone and esculetin in a mouse model of Parkinson's disease. $J$. Neurosci. Res., 91, 453-461 (2013).

19) Rodríguez-López JN, Fenoll LG, García-Ruiz PA, Varón R, Tudela J, Thorneley RN, García-Cánovas F. Stopped-flow and steady-state study of the diphenolase activity of mushroom tyrosinase. Biochemistry, 39, 10497-10506 (2000).

20) Bradford MM. A rapid and sensitive method for the quantitation of microgram quantities of protein utilizing the principle of proteindye binding. Anal. Biochem., 72, 248-254 (1976).

21) García-Molina F, Muñoz JL, Varón R, Rodríguez-López JN, García-Cánovas F, Tudela J. A review on spectrophotometric methods for measuring the monophenolase and diphenolase activities of tyrosinase. J. Agric. Food Chem., 55, 9739-9749 (2007).

22) Rodríguez-López JN, Ros-Martínez JR, Varón R, García-Cánovas F. Calibration of a Clark-type oxygen electrode by tyrosinasecatalyzed oxidation of 4-tert-butylcatechol. Anal. Biochem., 202, 356-360 (1992).

23) Salagoity-Auguste MH, Tricard C, Sudraud P. Simultaneous analysis of aromatic aldehydes and coumarins with high pressure liquid chromatography. Application to wines and brandies stored in oak barrels. J. Chromatogr. A, 392, 379-387 (1987). 
24) Jandel Scientific. Sigma Plot 9.0 for Windows ${ }^{\mathrm{TM}}$, Jandel Scientific: Core Madera (2006).

25) Muñoz JL, García-Molina F, Varón R, Rodríguez-López JN, García-Cánovas F, Tudela J. Calculating molar absorptivities for quinones: application to the measurement of tyrosinase activity. Anal. Biochem., 351, 128-138 (2006).

26) Muñoz-Muñoz JL, García-Molina F, Varón R, Rodríguez-López JN, García-Cánovas F, Tudela J. Kinetic characterization of the oxidation of esculetin by polyphenol oxidase and peroxidase. Biosci. Biotechnol. Biochem., 71, 390-396 (2007).

27) Fenoll LG, Rodríguez-López JN, García-Sevilla F, García-Ruiz PA, Varón R, García-Cánovas F, Tudela J. Analysis and interpretation of the action mechanism of mushroom tyrosinase on monophenols and diphenols generating highly unstable $o$-quinones. Biochim. Biophys. Acta, 1548, 1-22 (2001).

28) Ros JR, Rodríguez-López JN, García-Cánovas F. Tyrosinase: kinetic analysis of the transient phase and the steady state. Biochim. Biophys. Acta, 1204, 33-42 (1994).

29) Jiménez M, García-Carmona F. Hydroxylating activity of tyrosinase and its dependence on hydrogen peroxide. Arch. Biochem. Biophys.,
373, 255-260 (2000).

30) Jiménez M, García-Carmona F. Hydrogen peroxide-dependent 4-tbutylphenol hydroxylation by tyrosinase-A new catalytic activity. Biochim. Biophys. Acta, 1297, 33-39 (1996).

31) Yamazaki $S$, Morioka $C$, Itoh $S$. Kinetic evaluation of catalase and peroxygenase activities of tyrosinase. Biochemistry, 43, 1154611553 (2004).

32) Rodríguez-López JN, Tudela J, Varón R, García-Cánovas F. Kinetic study on the effect of $\mathrm{pH}$ on the melanin biosynthesis pathway. Biochim. Biophys. Acta, 1076, 379-386 (1991).

33) García-Moreno M, Rodríguez-López JN, Martínez-Ortiz F, Tudela J, Varón R, García-Cánovas F. Effect of $\mathrm{pH}$ on the oxidation pathway of dopamine catalyzed by tyrosinase. Arch. Biochem. Biophys., 288, 427-434 (1991).

34) Muñoz-Muñoz JL, García-Molina F, García-Ruiz PA, Varón R, Tudela J, García-Cánovas F, Rodríguez-López JN. Some kinetic properties of deoxytyrosinase. J. Mol. Catal., B Enzym., 62, 173182 (2010). 